\title{
Erratum to: Gastrointestinal tract access for enteral nutrition in critically ill and trauma patients: indications, techniques, and complications
}

\author{
M. Tuma $\cdot$ R. Latifi $\cdot$ A. El-Menyar • \\ H. Al-Thani
}

Published online: 15 May 2013

(C) Springer-Verlag Berlin Heidelberg 2013

\section{Erratum to: Eur J Trauma Emerg Surg}

\section{DOI 10.1007/s00068-013-0274-6}

In the published review article, the family name of the first author M. Tuna is not given correct. The correct name is: M. Tuma (not Tuna). In the "Methods" section, "We found 44 articles relevant to.........." should read as "We reviewed 86 articles, out of them 44 were relevant to.......".

The online version of the original article can be found under doi:10.1007/s00068-013-0274-6.

M. Tuma · R. Latifi $(\bowtie) \cdot$ A. El-Menyar · H. Al-Thani

Department of Surgery, Trauma Surgery Section,

Hamad General Hospital (HGH), Hamad Medical

Corporation, Doha, Qatar

e-mail: rlatifi@email.arizona.edu

R. Latifi

Department of Surgery, University of Arizona,

Tucson, AZ, USA

R. Latifi · A. El-Menyar

Weill Cornell Medical School, Doha, Qatar 